\title{
A Normalized Difference Vegetation Index (NDVI) Time-Series of IDLe Agriculture Lands: A Preliminary STUdY
}

\author{
Chaichoke Vaiphasa ${ }^{1 *}$, Supawee Piamduaytham², \\ Tanasak Vaiphasa ${ }^{3}$, and Andrew K. Skidmore ${ }^{4}$
}

1 Department of Survey Engineering, Faculty of Engineering, Chulalongkorn University, Bangkok 10330, Thailand

2 S\&S INCOM Co., Ltd. 69 Moo 10, Phungtru, Phanomthuan, Kanchanaburi 71140 Thailand

${ }^{3}$ Thailand Environmental Research, Education, Services Co.Ltd., Siam Square, Bangkok 10330, Thailand

4 ITC, Faculty of Geo-Information Science and Earth Observation of the University of Twente, the Netherlands

E-mail: chaichoke@hotmail.com and vaiphasa@alumni.itc.nl ${ }^{1}$

\section{ABSTRACT}

In this paper, the NDVI time-series collected from the study area between year 2003 and 2005 of all land cover types are plotted and compared. The study area is the agricultural zones in Banphai District, Khonkean, Thailand. The LANDSAT satellite images of different dates were first transformed into a time series of Normalized Difference Vegetation Index (NDVI) images before the investigation. It can be visually observed that the NDVI time series of the Idle Agriculture Land (IAL) has the NDVI values closed to zero. In other words, the trend of the NDVI values remains, approximately, unchanged about the zero level for the whole period of the study time. In contrast, the non-idle areas hold a higher level of the NDVI variation. The NDVI values above 0.5 can be found in these non-idle areas during the growing seasons. Thus, it can be hypothesized that the NDVI time-series of the different land cover types can be used for IAL classification. This outcome is a prerequisite to the follow-up study of the NDVI pattern classification that will be done in the near future.

\section{KEYWORDS}

classification, crop, idle agriculture land, NDVI, remote sensing, vegetation 


\section{Introduction}

Idle Agriculture Land (IAL)* is a serious issue for developing countries such as Thailand. The expanding size of Thailand's IAL directly links to major economic problems of the country (e.g., the lost of the national income from the agricultural sector, the decline in agricultural employment, poverty). According to the Thai government's report [1], the country has, in total, $12,000 \mathrm{KM}^{2}$ declared as IAL. The government has thus implemented a number of spatialbased measures to solve this IAL problem. Most of these government's measures started with an estimation of the locations and sizes of the IAL and then followed by a launch of tailor-made land management policies [1]. ("Agriculture lands that are not under any production/cultivation that is set at rest for a time period more than one year)

It has been verified by many researchers that remote sensing technology is a cost-effective tool for location-based crop and vegetation studies [2-10]. It significantly helps shorten the study time, thereby reducing the expense of the fieldwork. Even if the capabilities of remote sensing for spatial-based agricultural studies have been confirmed [11], there are very few direct studies that apply remote sensing to the IAL problems. So far, in Thailand, we can only find one effort that used remote sensing for identifying the IAL [12]. The study used a False Color Composite method to transform a series of multispectral satellite images, and then visually interpreted them. Unfortunately, this method is not popular by modern standards of remote sensing as it solely depends on subjective decisions of the interpreter. Additionally, it is quite laborious if the size of the study areas is large.

Therefore, this study intends to demonstrate a more subjective method to deal with the IAL problem. The proposed technique utilizes the NDVI time-series derived from multi-date LANDSAT satellite images. The study area is agricultural zones of Banphai District, Khonkean, Thailand. The NDVI time-series of different land cover types is to be plotted and compared. However, the results of this study cannot be used to make any conclusion whether the IAL can be discriminated from its surroundings. The follow-up study on the NDVI pattern classification is required before the conclusion can be made.

\section{Study Area}

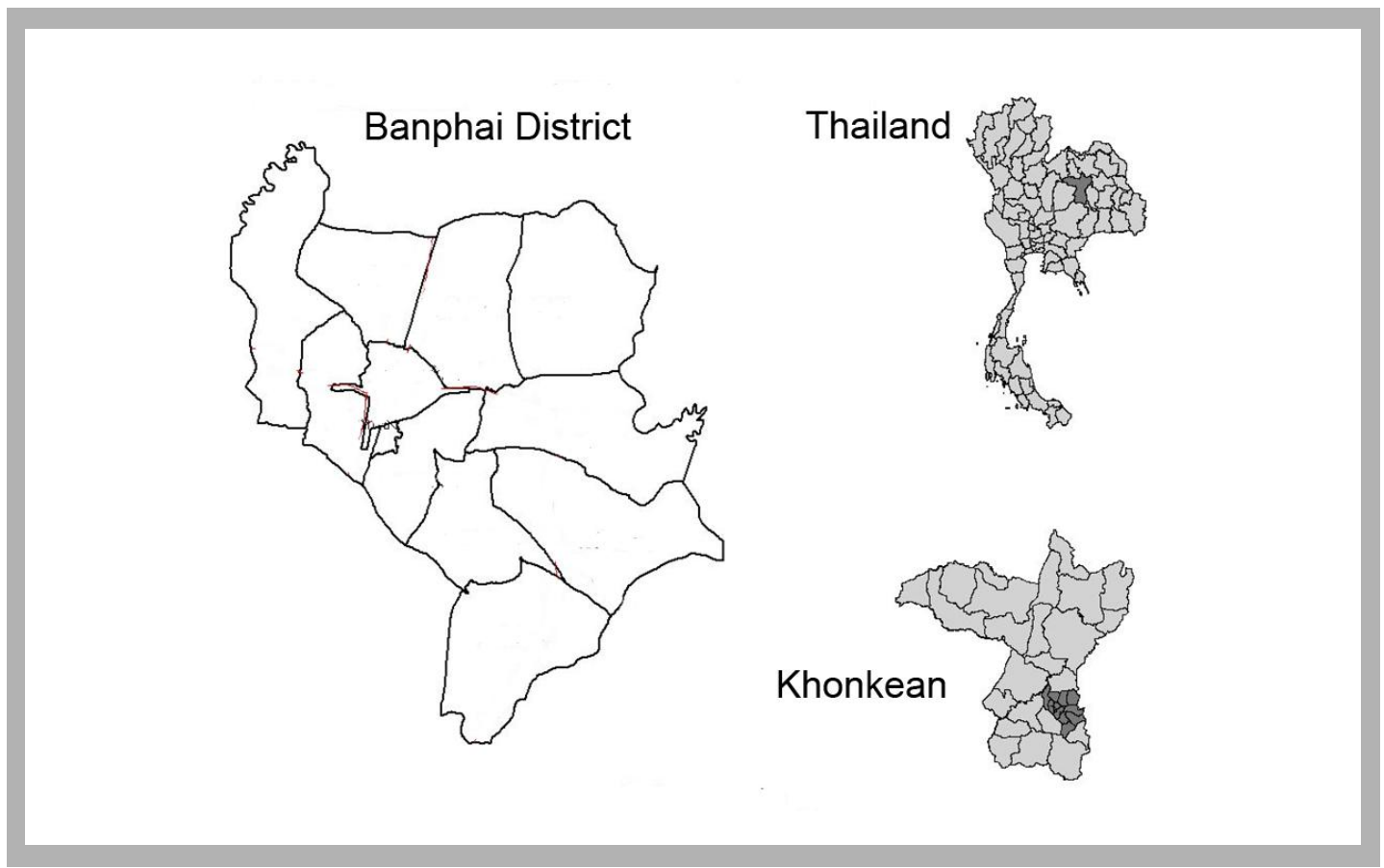

Figure 1

The study area depicted in Figure 1 is the agricultural zones in Banphai District, Khonkean, Thailand $\left(16^{\circ} 3^{\prime} 36^{\prime \prime} \mathrm{N}, 102^{\circ} 43^{\prime} 51^{\prime \prime} \mathrm{E}, 477.7 \mathrm{KM}^{2}\right)$. The background soil character is dominated by a sandy clay texture. The quality of the soils is being degraded by the salinity and erosion problems. Three major crops of this area are rice, sugar cane, and cassava. Banphai is one of the agricultural areas that are now facing with the IAL problems. 


\section{Satellite Imagery}

\begin{tabular}{|c|c|c|c|}
\hline NO. & Date Acquired & Satellite & Sensor \\
\hline 1 & 25 Mar 2003 & LANDSAT-7 & ETM+ \\
\hline 2 & 28 May 2003 & LANDSAT-7 & ETM+ \\
\hline 3 & 20 Dec 2003 & LANDSAT-5 & TM \\
\hline 4 & 24 Apr 2004 & LANDSAT-5 & TM \\
\hline 5 & 27 Sep 2004 & LANDSAT-5 & TM \\
\hline 6 & 16 Dec 2004 & LANDSAT-5 & TM \\
\hline 7 & 6 Mar 2005 & LANDSAT-5 & TM \\
\hline 8 & 7 Apr 2005 & LANDSAT-5 & TM \\
\hline 9 & 1 Nov 2005 & LANDSAT-5 & TM \\
\hline 10 & 21 Feb 2006 & LANDSAT-5 & TM \\
\hline 11 & 13 Jun 2006 & LANDSAT-5 & TM \\
\hline 12 & 22 Dec 2006 & LANDSAT-5 & TM \\
\hline
\end{tabular}

Twelve multi-date LANDSAT images listed in Table 1 are used for this study. All of them are of Path 128/Row 49. The images were rectified and geo-referenced to the WGS 84 datum on the UTM coordinate system (Zone 48N).

\section{NDVI Time-series}

All of the LANDSAT satellite images were transformed into an NDVI time-series following the equation below.

$$
\mathbf{N D V I}=\frac{(\mathbf{N I R}-\mathbf{R})}{(\mathbf{N I R}+\mathbf{R})}
$$

Band 4 of the LANDSAT images were input as the NIR variable, and Band 3 were placed at the $R$ variable of the equation.

\section{Results \& Discussion}

The NDVI time-series collected from the study area between year 2003 and 2005 of all land cover types are plotted and compared in this section. Firstly, the NDVI time series of rice paddy fields is plotted in Figure 2. The NDVI pattern of the rice paddy fields varies up and down throughout the years of study. The variation agrees with the local crop calendar as it increases during the growing periods and reaches the peaks just before the cultivation periods. These peaks can be clearly noticed at 27 Sep 2004 and 1 Nov 2005 in the plot. 


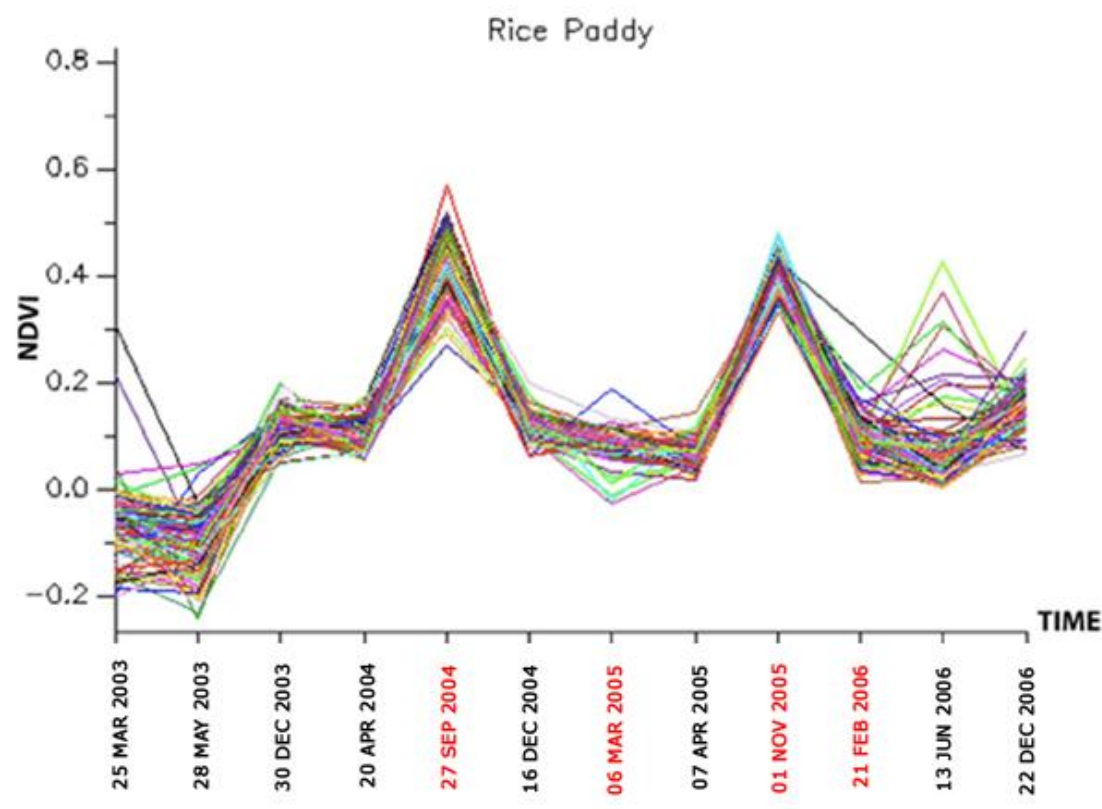

Figure 2

Secondly, the NDVI pattern of the cassava fields plotted in Figure 3 is different from the pattern of the rice paddy fields. According to the local crop calendar, the majority of the farmers grows the cassavas around the mid of the years. This activity is responsible for the peaks of the NDVI patterns at 27 September 2004 and 13 June 2006. However, it is clear that the variation also has other peaks scattered throughout the years. This is because the minority of the farmers grows the crop at different times of the years as reported in the crop calendar.

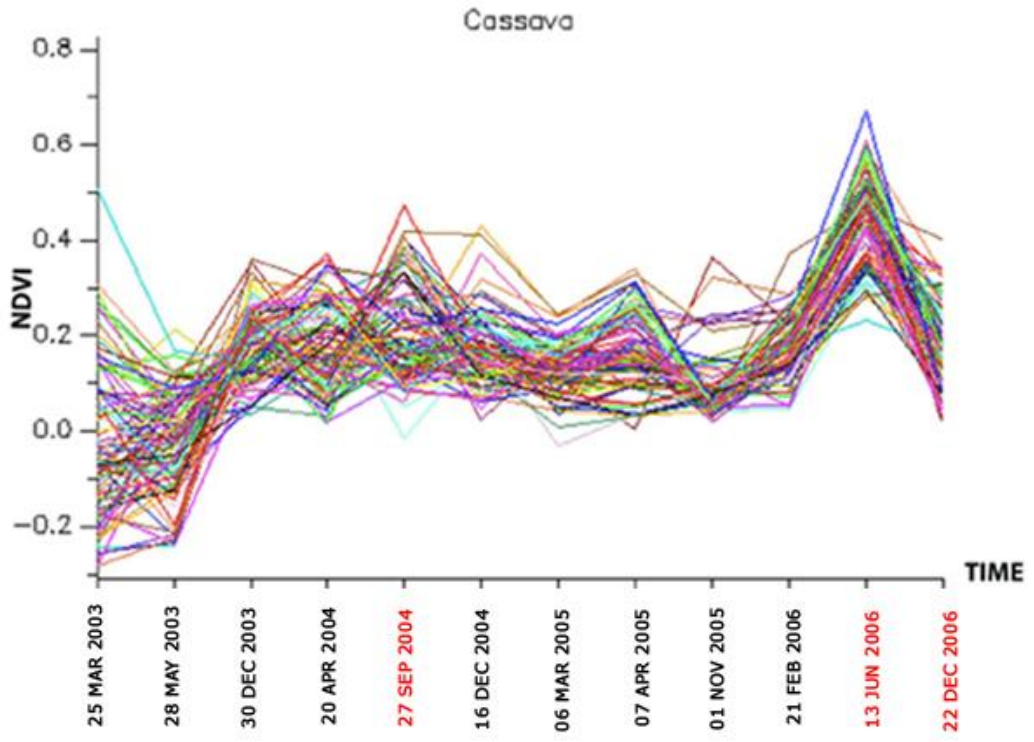

Thirdly, the repetition of the NDVI pattern of the sugar cane is noticeable in Figure 4. The peaks of the NDVI values can be found at the end of each year. Then, the NDVI values drop to the near-zero values. According to the local crop calendar, these drops reflect the cultivation phases of the sugar cane. 
Figure 4

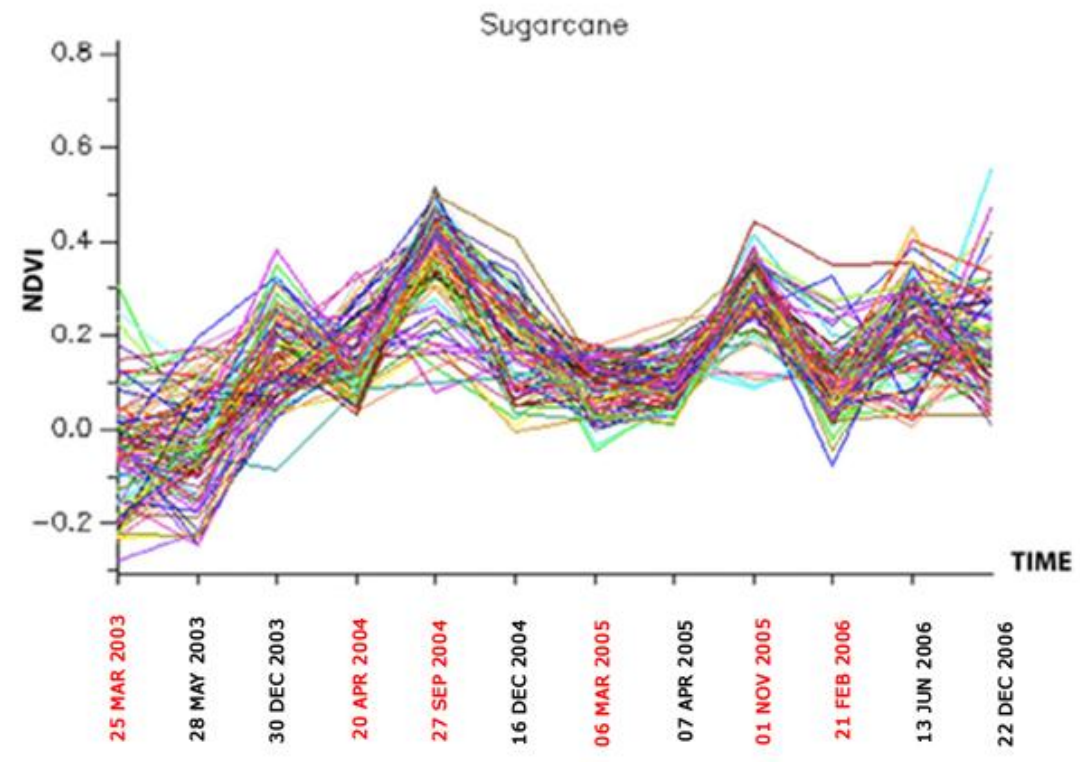

Fourthly, the NDVI time series of grass lands is plotted in Figure 5. The NDVI response of the grass lands is similar to the NDVI pattern of the sugar canes. The peaks of the NDVI values can be noticed at the end of each year. This pattern reflects seasonal variations of the grass as it gains the maximum level of biomasses at the end of the year.

Figure 5

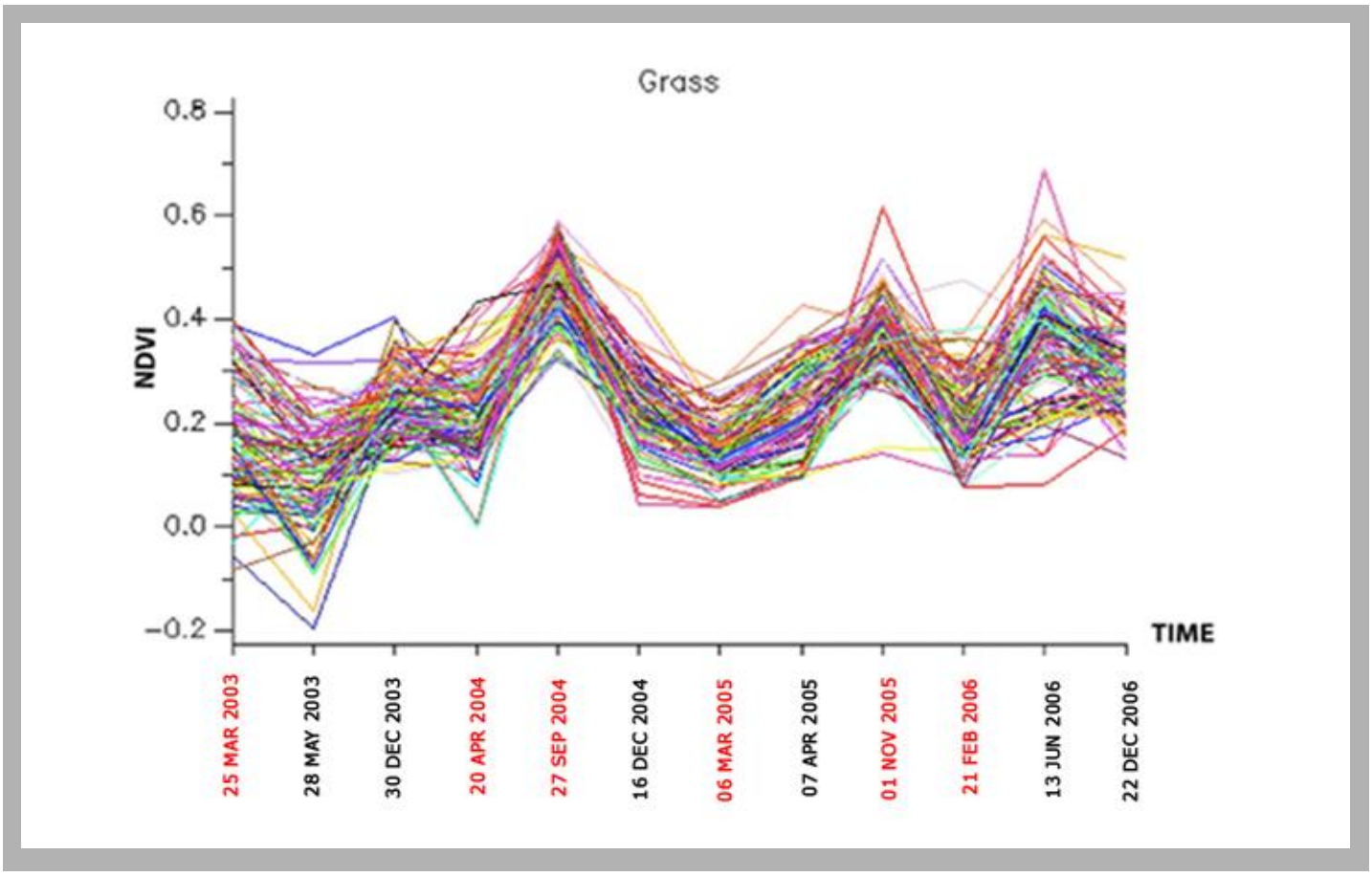

Next, the NDVI time series of the IAL is plotted in Figure 6. The characteristic of the NDVI curves captured from the IAL is different from the NDVI curves captured from the other land cover types. The NDVI pattern of the IAL areas stays at the level of low NDVI values. 


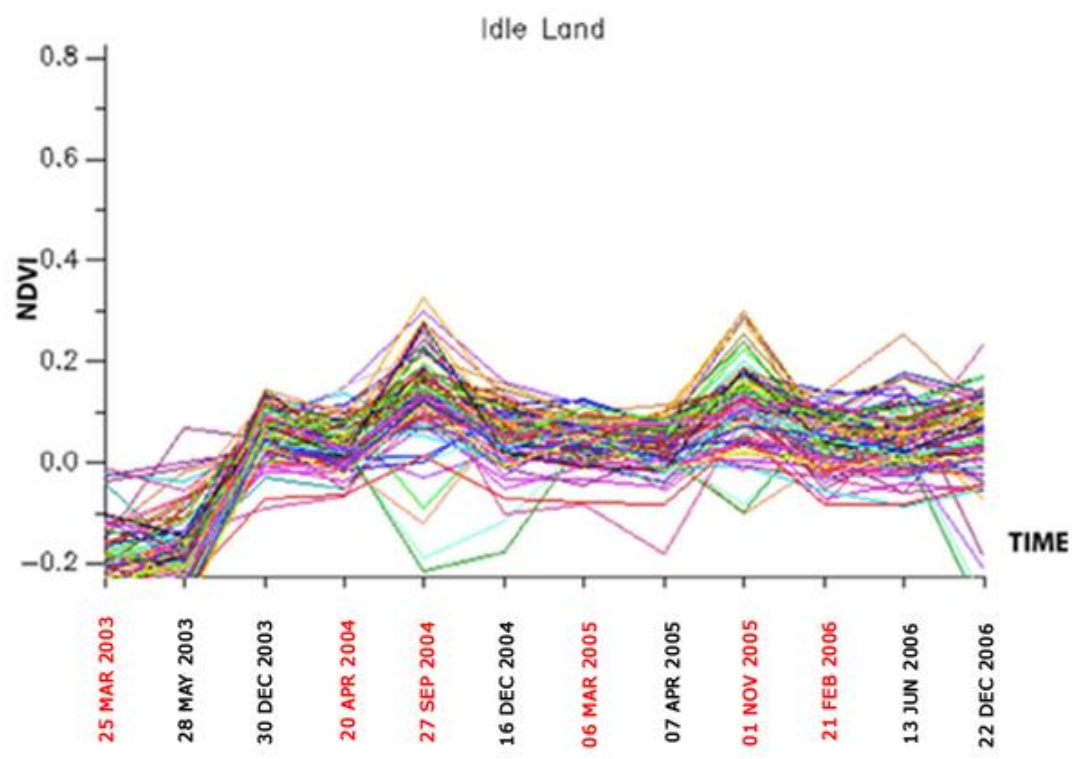

Figure 6

Lastly, the mean of every plot is plotted against each other in Figure 7. The NDVI curve of the IAL can be visually spotted as it has the lowest NDVI values.

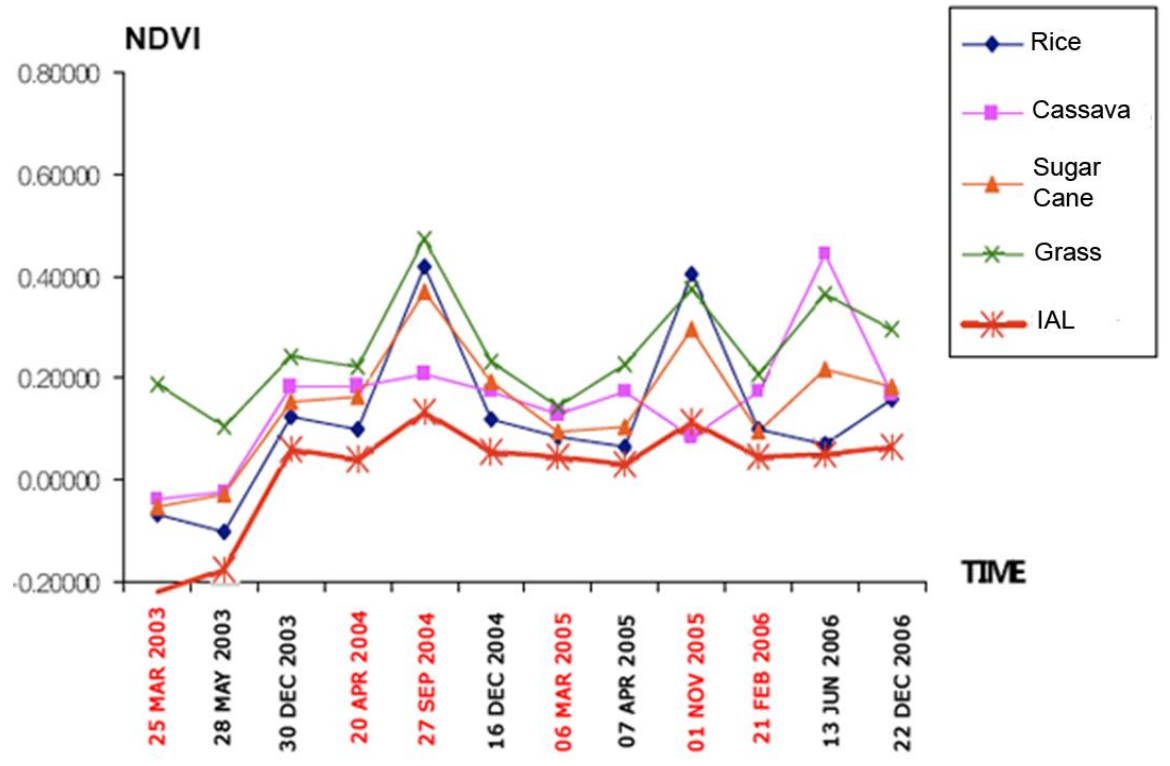

Figure 7

\section{Conclusion}

This NDVI time-series of 5 different land cover types were plotted and compared in this study. It is clear that the NDVI pattern of the IAL can be separated from the NDVI patterns of the other land cover types. Additionally, it is found that the NDVI patterns also agree with the local crop calendar. In other words, the ups and downs of the curves respectively reflect the high and low of the biomass levels of the crops. This outcome is a prerequisite to the followup study of the NDVI pattern classification that will be done in the near future. 


\section{ACKNOWLEDGEMENT}

This work is financially-support by the post-doc program of the Teacher Development Scholarships program (CHE-RES-PD) of Commission on Higher Education, Thailand. The satellite images used in this work is supported by GISTDA, Thailand. 


\section{REFERENCES}

[1] Land Development Department, Idle Lands.(in Thai) 2010, [Online]. Available: http://irw101.Idd.go.th/irw101.Idd/topic4_old.php?page=7 [Accessed Dec. 30, 2010].

[2] B. C. Reed, J. F. Brown, D. VanderZee, T. R. Loveland, J. W. Merchant, and D. O. Ohlen, "Measuring phenological variability from satellite imagery," Journal of Vegetation Science, vol. 5, no. 5, pp. 703-714, Nov.1994.

[3] B. C. Reed, T. R. Loveland, and L. L. Tieszen, "An approach for using AVHRR data to monitor U.S. great plains grasslands," Geocarto International, vol. 11, no. 3, pp.13-22, Sep. 1996.

[4] G. J. Lyon, D. Yuan, R. S. Lunetta, and C. D. Elvidge, "A change detection experiment using vegetation indices," Photogrammetric Engineering and Remote Sensing, vol. 64, no. 2, pp. 143-150, Feb. 1998.

[5] J. F. Mass, "Monitoring land cover changes: a comparison of change detection techniques," International Journal of Remote Sensing, vol. 20, no. 1, pp. 139-152, Jan. 1999.

[6] C. E. Woodcock, S. A. Macomber, M. Pax-Lenney, and W. B. Cohen, "Monitoring large areas for forest change using Landsat: generalization across space, time and Landsat sensors," Remote Sensing of Environment, vol. 78, no. 1-2, pp. 194-203, Oct. 2001.

[7] M. E. Jakubauskas, D. L. Peterson, J. H. Kastens, and D. R. Legates, "Time series remote sensing of landscape-vegetation interactions in the southern Great Plains," Photogrammetric Engineering and Remote Sensing, vol. 68, no. 10, pp. 1021-1030, Oct. 2002.

[8] X. Zhang, M. A. Friedl, C. B. Schaaf, A. H. Strahler, J. C. F. Hodges, and F. Gao, "Monitoring vegetation phenology using MODIS," Remote Sensing of Environment, vol. 84, no. 3, pp. 471-475, Mar. 2003.

[9] J. R. Jensen, Remote Sensing of the Environment: an Earth Resource Perspective, Upper Saddle River, NJ: Prentice Hall, 2007.

[10] C. Vaiphasa, W. F. de Boer, A. K. Skidmore, S. Panitchart, T. Vaiphasa, N. Bamrongrugsa, and P. Santitamnont, "Impact of solid shrimp pond waste materials on mangrove growth and mortality: a case study from Pak Phanang,Thailand," Hydrobiologia, vol. 591, no. 1, pp. 47-57, Oct. 2007.

[11] K. Green, D. Kempka, and L. Lackey, "Using remote sensing to detect and monitor land-cover and land-use change," Photogrammetric Engineering \& Remote Sensing, vol. 60, no. 3, pp. 331-337, Jan. 1994.

[12] S. Pititeeraparb, Idle Agriculture Land Survey in Thailand: A Survey and Utilization (in Thai). Bangkok: Land Development Department, pp. $1-153,2005$. 